NBER WORKING PAPER SERIES

THE LIFE CYCLE OF SCHOLARLY ARTICLES ACROSS FIELDS OF RESEARCH

\author{
Sebastian Galiani \\ Ramiro H. Gálvez \\ Working Paper 23447 \\ http://www.nber.org/papers/w23447
}

NATIONAL BUREAU OF ECONOMIC RESEARCH

1050 Massachusetts Avenue

Cambridge, MA 02138

May 2017

The authors thank Lee Benham for valuable suggestions and comments. The views expressed herein are those of the authors and do not necessarily reflect the views of the National Bureau of Economic Research.

NBER working papers are circulated for discussion and comment purposes. They have not been peerreviewed or been subject to the review by the NBER Board of Directors that accompanies official NBER publications.

(C) 2017 by Sebastian Galiani and Ramiro H. Gálvez. All rights reserved. Short sections of text, not to exceed two paragraphs, may be quoted without explicit permission provided that full credit, including (C) notice, is given to the source. 
The Life Cycle of Scholarly Articles across Fields of Research

Sebastian Galiani and Ramiro H. Gálvez

NBER Working Paper No. 23447

May 2017

JEL No. B0

\begin{abstract}
Aggregate citation behavior plays a key role in scientific knowledge diffusion, as citations document the collective and cumulative nature of knowledge production. Additionally, citations are commonly taken as input for several influential evaluative metrics used to assess researchers' performance. Nevertheless, little effort has been devoted to understanding and quantifying how article citations evolve over the years following an article's publication and how these trends vary across fields of research. By collecting and analyzing a dataset consisting of more than five million citations to 59,707 research articles from 12 dissimilar fields of research, we quantify how citations evolve across fields of research as articles grow older. Analyzing raw citation data spanning different periods poses several methodological challenges; to tackle them, we employ quantile regression, a technique that makes it possible to control for citation inflation (the fact that citations have become more common nowadays) and to take into consideration the well-known asymmetry in the distribution of citations. We find that citations follow a life-cycle pattern. In the first years after publication, articles generally receive a small but growing number of citations until, eventually, they reach a peak from which they then decline. Importantly, the shape of these life cycles varies greatly from one field to the next. Given that several influential metrics restrict their input to a certain range in terms of the number of years since publication, these differences are by no means neutral and should be taken into account when evaluating researchers or their institutions.
\end{abstract}

Sebastian Galiani

Department of Economics

University of Maryland

3105 Tydings Hall

College Park, MD 20742

and NBER

galiani@econ.umd.edu

Ramiro H. Gálvez

Facultad de Ciencias Exactas

Ciudad Autonoma de Buenos Aires

Argentina

ramirogalvez@gmail.com 


\title{
The life cycle of scholarly articles across fields of research
}

\author{
Sebastian Galiani*a,b and Ramiro H. Gálvez ${ }^{\dagger c}$ \\ a Department of Economics, University of Maryland, College Park, MD 20742. \\ ${ }^{\mathrm{b}}$ National Bureau of Economics Research, Cambridge, MA 02138 \\ ${ }^{\mathrm{c}}$ Department of Computer Science, Facultad de Ciencias Exactas y Naturales, Universidad de Buenos Aires, Buenos \\ Aires, Argentina C1428EGA.
}

May 2, 2017

\begin{abstract}
Aggregate citation behavior plays a key role in scientific knowledge diffusion, as citations document the collective and cumulative nature of knowledge production. Additionally, citations are commonly taken as input for several influential evaluative metrics used to assess researchers' performance. Nevertheless, little effort has been devoted to understanding and quantifying how article citations evolve over the years following an article's publication and how these trends vary across fields of research. By collecting and analyzing a dataset consisting of more than five million citations to 59,707 research articles from 12 dissimilar fields of research, we quantify how citations evolve across fields of research as articles grow older. Analyzing raw citation data spanning different periods poses several methodological challenges; to tackle them, we employ quantile regression, a technique that makes it possible to control for citation inflation (the fact that citations have become more common nowadays) and to take into consideration the well-known asymmetry in the distribution of citations. We find that citations follow a life-cycle pattern. In the first years after publication, articles generally receive a small but growing number of citations until, eventually, they reach a peak from which they then decline. Importantly, the shape of these life cycles varies greatly from one field to the next. Given that several influential metrics restrict their input to a certain range in terms of the number of years since publication, these differences are by no means neutral and should be taken into account when evaluating researchers or their institutions.
\end{abstract}

Keywords: citation analysis | scientific knowledge diffusion | quantile regression $\mid$ scientometrics

Understanding the creation and flow of knowledge is a topic of great concern both in academia and in

\footnotetext{
*galiani@econ.umd.edu

†rgalvez@dc.uba.ar
}

policymaking, as it is considered to be a key driver of economic growth and prosperity [1, 2, 3]. When the area of knowledge under consideration is narrowed to that of scientific knowledge, interest is usually centered on its flow within and between scientific areas, which is traced through citations in scientific publications [4, 5, 6]. In this sense, citations serve to document the collective and cumulative nature of knowledge production [7]. Citations also influence knowledge creation and diffusion in a less direct, but by no means negligible, way: many of the influential metrics used to evaluate researchers and research institutions are based on citation counts [8, 9, 10, 11]. This is a topic of debate and concern in the scientific community, and opposing views regarding the issue are held [12]. On the one hand, proponents of the use of citation counts argue that metrics, if correctly used, provide transparency and objectivity in evaluating researchers' performance. On the other hand, there is also a widespread perception that metrics can be manipulated and that their use crowds out valuable qualitative reviews.

One of the main reasons for the widespread use of bibliometric indices is that, once citation data are available, calculating them is relatively easy or even trivial. Take the cases of the Hirsch's $h$-index and the journal impact factor, two popular evaluative metrics. The Hirsch's $h$-index is defined as the largest 
number $h$ such that the researcher being evaluated has published $h$ articles such that each of them is cited $h$ or more times [13, 14, 15]. The $n$-year journal impact factor, for any given year, is defined as the average number of citations received by papers published in the journal during the $n$ preceding years (typically, $n$ equals 2 or 5 years) [16, 17, 18]. In terms of computation, the first index involves sorting authors' articles in ascending order by the number of total citations and checking which one is the last one for which a simple condition is satisfied, whereas the second involves calculating a simple arithmetic mean.

Even though calculating these metrics from citation data is an easy task, citation behavior (i.e., the data generation process) is a complex phenomenon [19] which is influenced by many factors besides scientific merit (understood in terms of quality or relevance). Among these various elements, two stand out. First, citations are presumed to be influenced by field-dependent factors. For example, in some fields, recent papers are cited more frequently than in some others [20], and literature in relatively small and isolated fields attracts fewer citations than more general papers do [19, 21]. Second, citation activities are also influenced by time-dependent factors Concretely, as the number of publications in peerreviewed journals steadily grows [22], and as newer articles tend to cite more sources than older ones [23], citations have become more common from year to year. Following [23] and [24], we refer to this phenomenon as citation inflation.

Surprisingly, even though citation behavior is regarded as an important issue, little effort has been devoted in either studies on scientific knowledge diffusion or the evaluative bibliometric literature to understanding and quantifying how article citations evolve as articles grow older. The importance of these trends is by no mean negligible, given that, as citation indices usually restrict the range of articles that they use as input on the basis of the number of years that have passed since their publication, annual trends in citations may strongly influence the values of these indices. Furthermore, it is not clear how these dynamics vary across different fields of research or how they are affected by citation inflation. For example, for a metric that excludes citations coming from articles that are older than 2 or 5 years, disciplines in which articles receive most of their citations in the first few years after publication may be perceived as more influential or important than disciplines in which article citations take longer to reach a peak. The fact that these patterns are not well understood suggests that caution should be used when comparing researchers across disciplines or even when comparing researchers who are at different stages of their careers. In this study, we help to fill this gap by identifying, analyzing, and quantifying annual trends in citations as articles grow older. In doing so, we place a strong emphasis on the analysis of differences across a broad range of disciplines and across articles having different levels of success (as measured by citation counts).

\section{Results}

To arrive at our results, we collected detailed Google citation data on more than five million citations spanning 59,707 research articles and 12 fields of research (astronomy \& astrophysics, biochemistry, biology, economics, finance, mathematics, medicine, physics, political science, psychology, sociology, and statistics). As detailed in Materials and Methods, an important and distinctive feature of our analysis is that, when sampling these articles, we took special care to obtain a representative sample of articles across fields of research, time, and level of success.

To place our results in context, we first show that, at the stock level (i.e., considering total citation counts), citation counts vary greatly across fields of research. Then, we show how raw annual trends in citations vary across these fields. In doing so, we make explicit the importance of taking into account citation inflation and skewness in the distribution of citations. Finally, and taking into consideration both of these issues, we present our estimates of the 
Table 1: Summary statistics of Google citation data at the article level across fields of research (1985-2000)

\begin{tabular}{|c|c|c|c|c|c|c|c|c|c|}
\hline Field of Research & Median & $\begin{array}{c}\text { Quantile } \\
0.75\end{array}$ & $\begin{array}{c}\text { Quantile } \\
0.95\end{array}$ & $\begin{array}{c}\text { Quantile } \\
0.99\end{array}$ & Mean & $\begin{array}{l}\text { Standard } \\
\text { deviation }\end{array}$ & $\begin{array}{l}\text { Citations of the } \\
\text { most cited article }\end{array}$ & $\begin{array}{c}\text { Total } \\
\text { citations }\end{array}$ & $\begin{array}{l}\text { Number of } \\
\text { articles }\end{array}$ \\
\hline Astronomy \& Astrophysics & 25 & 54.00 & 163.00 & 360.46 & 47.83 & 85.62 & 3,231 & 400,751 & 8,378 \\
\hline Biochemistry & 39 & 73.00 & 187.00 & 366.72 & 63.52 & 267.51 & 33,955 & $1,170,598$ & 18,429 \\
\hline Biology & 62 & 192.25 & 679.70 & $1,372.51$ & 173.29 & 335.83 & 6,485 & 395,790 & 2,284 \\
\hline Economics & 85 & 230.50 & 879.00 & $2,036.60$ & 227.88 & 505.20 & 13,270 & 563,095 & 2,471 \\
\hline Finance & 78 & 200.00 & 834.85 & $1,984.69$ & 213.61 & 486.29 & 11,094 & 350,751 & 1,642 \\
\hline Mathematics & 27 & 58.00 & 148.00 & 281.00 & 45.70 & 61.76 & 772 & 73,527 & 1,609 \\
\hline Medicine & 45 & 135.00 & 598.00 & $1,356.39$ & 139.69 & 295.90 & 4,190 & 731,161 & 5,234 \\
\hline Physics & 26 & 61.00 & 198.10 & 467.10 & 56.93 & 115.63 & 3,319 & 717,247 & 12,599 \\
\hline Political Science & 47 & 107.00 & 314.50 & 907.50 & 93.54 & 167.87 & 2,820 & 118,420 & 1,266 \\
\hline Psychology & 52 & 104.00 & 288.80 & 713.54 & 91.23 & 137.61 & 1,785 & 186,473 & 2,044 \\
\hline Sociology & 57 & 132.50 & 411.40 & $1,104.34$ & 125.32 & 294.48 & 5,071 & 146,245 & 1,167 \\
\hline Statistics & 30 & 68.00 & 245.85 & 605.00 & 69.52 & 158.92 & 2,794 & 179,637 & 2,584 \\
\hline
\end{tabular}

This table includes only citations of articles made in the period starting two years before their publication and ending fifteen years after publication.

life-cycle pattern of citations across different fields of research.

\section{Total citations across fields of research}

Table 1 contains summary statistics for citation data at the article level across the listed fields of research for our sample of articles published between 1985 and 2000.

Table 1 shows that aggregate citation patterns vary dramatically across different fields of research. While economics and finance have median citation values of 85 and 78, respectively, physics, mathematics, and astronomy \& astrophysics all have mean citation values close to 25 citations. Additionally, note that a strong positive asymmetry in the distribution of total citations is evident in every field of research (in all of them, the mean citation value far surpasses the median value).

\section{Raw annual trends in citations across fields of research}

Although static patterns such as those presented in Table 1 are interesting in and of themselves, they do not tell us anything about one important factor: the way an article is cited as it grows older varies greatly across fields of research. As a first attempt to shed

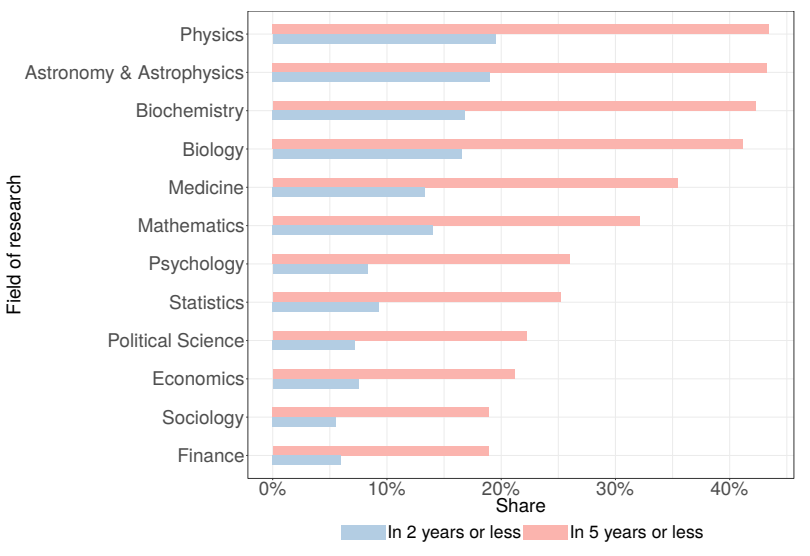

Fig. 1: Share of total citations received up to 2 and 5 years after publication relative to all citations received up to 15 years after publication. Estimates are presented for every field of research that was analyzed.

light on this pattern, Fig. 1 plots for each field of research the share of total citations received up to 2 and 5 years after publication relative to all citations received up to 15 years after publication. (Note that 2 and 5 years are the periods usually considered when calculating journal impact factors.)

Fig. 1 already points to the conclusion that citation dynamics vary greatly between fields of research. Notably, disciplines which appear to have great success in terms of citation counts (see Table 1) 
(e.g., economics and finance) tend to receive a small proportion of their citations in the first years after publication. This suggests that an important factor in driving the success of articles in those fields is that they are cited for longer periods rather than being the subject of a large surge in citations soon after their publication. Importantly, this also indicates that certain fields of research may be at an advantage or a disadvantage when they are compared to others on the basis of indices for all citations since publication or indices that include only the citations made in the first few years following publication.

To provide a better way of visualizing differences in the evolution of citations across fields of research, Fig. 2 plots the number of citations per year since publication for the mean paper (solid line) and the median one (dashed line) for each field of research 1 To illustrate the effect of citation inflation, this figure differentiates estimates for the group of articles published during the period from 1985 to 1989 (19851989, in blue) and for the group published in the period from 1995 to 1999 (1995-1999, in red).

It is clear from Fig. 2 that estimated trends differ greatly across fields of research. In disciplines such as physics, astronomy \& astrophysics, biochemistry, and biology, a clear-cut decline in the number of citations per year is observed after a period of time; in other disciplines, such as economics, finance, mathematics, political science, sociology, and statistics, non-descending curves are observed for mean citations per year.

Interestingly, Fig. 2 also makes explicit two features that should be taken into account when analyzing the evolution of citation behavior across time and across fields of research. First, the fact that curves for the period 1995-1999 always lie at higher values than

\footnotetext{
${ }^{1}$ If $c_{i, t}$ is the number of citations of paper $i$ received after $t$ years since publication, $r$ is the set of papers from a particular field of research (for a five-year period) and $n_{r}$ denotes the number of papers in field of research $r$ (for a five-year period). For papers corresponding to hand-picked five-year periods and for each field of research, Fig. 2 plots the evolution of $\sum_{i \in r} c_{i, t} / n_{r}$ for successive values of $t$, as well as the evolution of the median values of these citations.
}

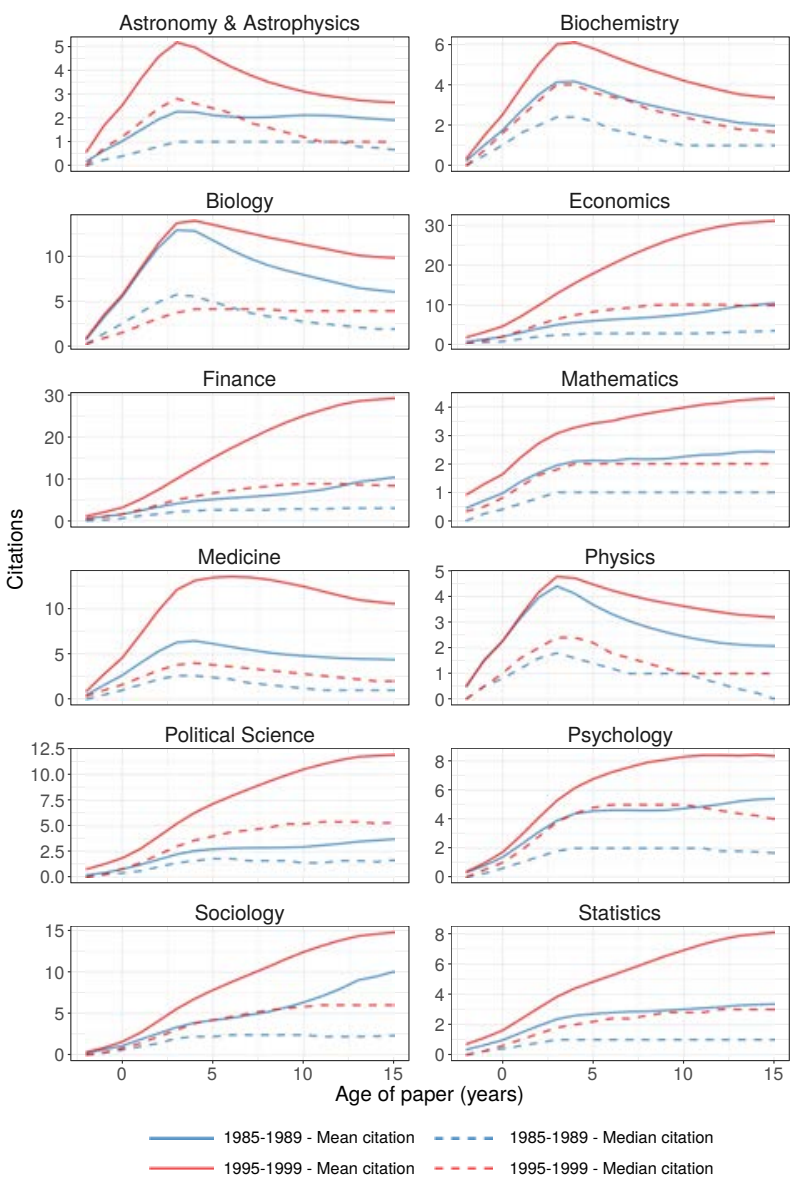

Fig. 2: Estimated annual trends in citations of the mean and median articles, by field of research. Estimates are calculated for articles published from 1985 up to 1989 and from 1995 up to 1999. Values are smoothed using five-year centered moving averages. Note that the $y$-axis scales vary across sub-figures.

the ones estimated for 1985-1989 signals the presence of citation inflation. Citation inflation makes it hard to determine if articles which accumulate more citations in their first years after publication relative to the ones accumulated by older articles over their entire lifespan are effectively more relevant or if this is just a consequence of citations becoming more common. Fig. 2 shows that citation inflation has not occurred at the same rate in all fields of research. Take the case of the increment in mean citations 
for medicine compared to biology or physics. For medicine, an article published in the period 19851999 received little more than five citations per year, on average, in its peak year, while, for the period 1995-1999, in its peak year it received almost three times more citations. On the other hand, in the fields of biology and physics, the peak in citations per year did not vary as much, but the newer articles tended to age better (i.e., the decay in annual citations was less pronounced). Second, the fact that mean citation curves for any given period lie at higher values than the curves for median citations signals the existence of a strong positive skewness in the distribution of citations per year. Note that this asymmetry in the distribution of citations is common to all fields of research and persists as the papers age. Nevertheless, the strength of this trend also seems to differ across fields. Let us consider, for example, the case of psychology and biochemistry as compared to biology, medicine and economics. In psychology and biochemistry, the mean estimates are as much as double the median values, while, in biology, medicine and economics, the mean estimates are more than quadruple the median ones.

\section{Life-cycle of scholarly articles across fields of research}

Annual citations are presumed to have a life-cycle: after publication, articles begin to be read and cited; eventually, the number of citations reaches a peak, after which it declines (probably because newer papers supplant the older articles). Associating articles' life cycles with raw citation trends, such as the ones presented in Fig. 2, is misleading, however, owing to the effect of citation inflation. Moreover, the skewness in the distribution of annual citations also suggests that associating life cycles with average values for citations may introduce a bias in the results.

In order to address both of these issues, in this study we identify the life cycles of research articles by means of quantile regression (QR) [25, 26]. $\mathrm{QR}$ is a regression technique used for estimating and conducting inference about conditional quantile functions. Just as ordinary least squares (OLS) regressions estimate models for conditional mean functions by minimizing sums of squared residuals, quantile regression estimates, through analogue minimizations, models for conditional median functions, as well as for a full range of other conditional quantiles. Using QR to estimate the life cycles of research articles offers several advantages. First, QR is more robust than OLS to the presence of skewness in the response variable distribution and to outliers. Second, by introducing dummy variables representing the year in which citations were received, estimates can be controlled for citation inflation. Third, estimating conditional quantiles of a response variable distribution makes it possible to examine not only the life cycles of "typical" or "central" articles, but also those of articles having different levels of conditional success.

Concretely, using QR and the collected citation data, for each field of research we fit the following regression model:

$$
c_{i, t}(\tau)=\beta_{0}(\tau)+\sum_{s \in S} \beta_{s}(\tau) I_{t, s}+\sum_{y \in Y} \gamma_{y}(\tau) I_{i, t, y}+\epsilon_{i, t}(\tau)
$$

where $c_{i, t}$ stands for citations of paper $i$ at age $t$ (years since publication, which range from -2 to 15). The set $S$ contains integers ranging from -2 to 15 except for 0 (which we set as our base category for years since publication). $I_{t, s}$ is an indicator variable that takes the value 1 if $t$ equals $s$ and 0 if not $\left.\right|^{2}$ The set $Y$ contains integers ranging from 1986 to 2015 which represent the calendar year in which citations were received. (Note that this specification leaves 1985 as our base category.) $I_{i, t, y}$ is another indicator variable that takes the value 1 if year $t$ is

\footnotetext{
${ }^{2}$ Suppose we are analyzing an article 10 years after its publication ( $t$ is equal to 10). In this case, $I_{t, s}$ equals 1 if and only if $s$ equals 10 , thereby neutralizing the effects of any coefficient $\beta_{s}(\tau)$ other than $\beta_{10}(\tau)$.
} 
the year when citations of paper $i$ after $y$ years of having been published were generated and 0 if not, which makes it possible to control for secular trends in citations (taking into account citation inflation) ${ }^{3}$ Finally, $\epsilon_{i, t}$ is an error term, and $\tau$ stands for the quantile of its distribution. Thus, the life-cycle of an article in a particular field of research can be identified by analyzing the trend of values obtained for $\beta_{0}(\tau)+\beta_{s}(\tau)$ at different values of $s$.

Fig. 3 presents the life-cycle of articles for every field of research that was analyzed as estimated by Eq. 1. For the sake of comparison with Fig. 2, apart from the QR estimates, we also present estimates obtained through OLS regressions (even though these estimates do not address asymmetry in the distribution of annual citations). The curves shown in purple correspond to life cycles as estimated on the basis of $\mathrm{QR}$ regressions; the curves shown in green correspond to life cycles as estimated on the basis of OLS regressions. Detailed estimated coefficients are presented in SI Appendix, Tables S1-S12.

When controlling for citation inflation, it is evident that, across all disciplines, annual citations exhibit a life-cycle pattern. Nevertheless, sharp differences are also observed between different fields of research. First, it is clear that the peak of annual citations is much higher for some disciplines than for others. For example, biology and medicine are research fields in which the peak level of annual citations is much higher than it is in fields such as mathematics and statistics. Second, the peak in citations is not reached at the same time across fields and, after this peak is reached, annual citation values differ in the way that they decline. For astronomy \& astrophysics, biochemistry, biology, medicine, and physics, a peak is reached before the fifth year after publication and, once this peak is reached, annual

\footnotetext{
${ }^{3}$ Suppose we are analyzing an article $i$ published in 1990, 10 years after its publication ( $t$ is equal to 10$)$. In this case, $I_{i, t, y}$ equals 1 if and only if $y$ is equal to 2000, thereby neutralizing the effect of any $\gamma_{y}(\tau)$ other than $\gamma_{2000}(\tau) \cdot \gamma_{2000}(\tau)$ captures the extra citations of paper $i$ after $t$ years of publication because those citations were generated in the year 2000 relative to the citations generated in 1985 (the base category).
}
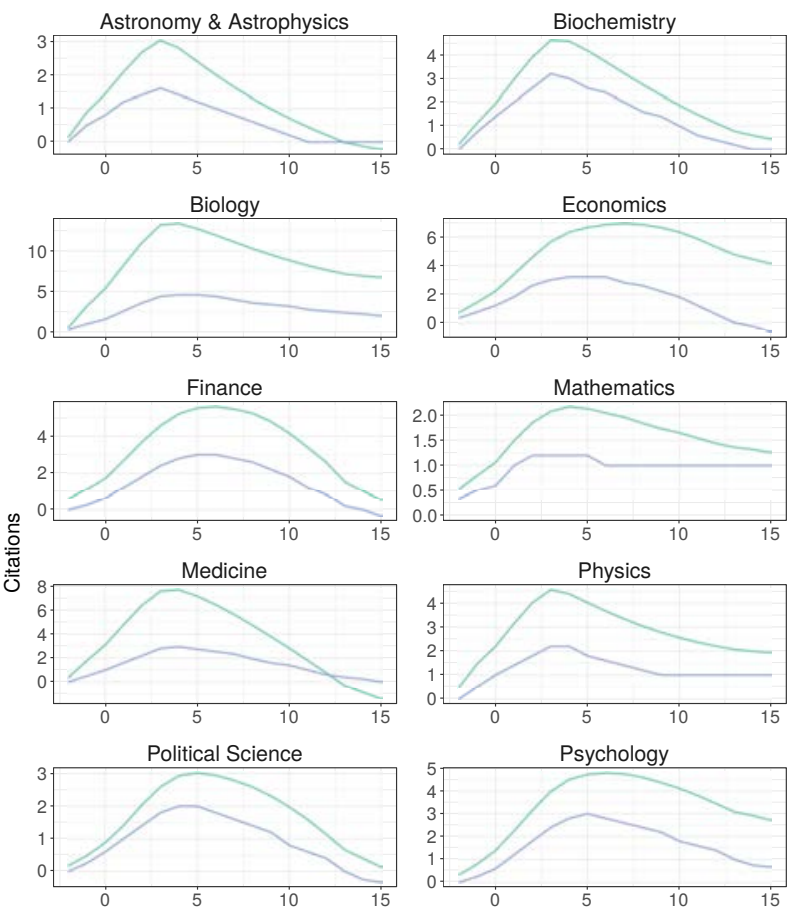

Sociology

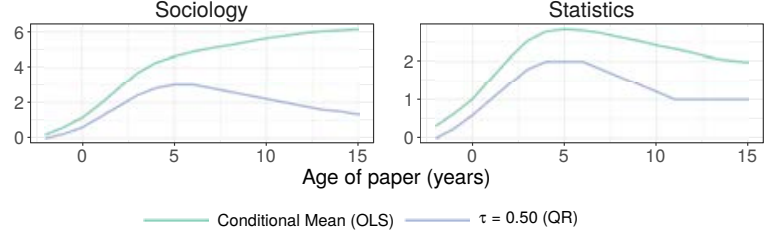

Fig. 3: Estimated life cycles of citations of research articles obtained by regression analysis. Estimations are presented for the conditional mean (estimated using OLS) and for $\tau=0.50$ (estimated using QR). Values are smoothed using five-year centered moving averages. Note that the $y$-axis scales vary across subfigures.

citations fall-off sharply. On the other hand, for economics, finance, political science, and sociology, the peak is reached in the fifth year after publication, but annual citations fall-off much more gradually from then on. Third, differences between QR and OLS estimates also vary greatly across disciplines. These patterns go hand in hand with the findings shown in Fig. 2 for disciplines such as biology, medicine and economics, the two values differ greatly, while 
for psychology and biochemistry, they do not ${ }^{4}$

As many bibliometric indices are especially sensitive to highly successful articles (e.g., total number of citations, average number of citations per paper, journal impact factors), understanding the dynamics of highly cited articles is also important in order to better understand the potential drawbacks associated with the use of these indices. In Fig. 4, we present the estimated life cycles obtained by using the specification presented in Eq. 1 for the 0.85 and 0.95 percentiles of the conditional distribution of the annual number of citations. Detailed estimated coefficients are presented in SI Appendix, Tables S1-S12.

Fig. 4 shows that, even for highly successful research articles, a life-cycle pattern is observed in all the disciplines covered by this study. Moreover, this figure again points to differences across disciplines. It is notable that, for disciplines which have a sharp peak in annual citations (i.e., astronomy \& astrophysics, biochemistry, biology, medicine and physics), the shape of the estimated life cycles remains quite constant relative to those presented in Fig. 3. with the major difference being that, in Fig. 4 these peaks represent higher annual citation values. This does not seem to hold for disciplines such as economics, finance, political science, sociology, and statistics, where highly successful articles not only reach higher peaks, but also seem to reach those peaks later than in the other disciplines mentioned above.

\section{Discussion and Conclusions}

The citations of other research articles that appear in scientific journals play a key role in the formation and diffusion of scientific knowledge, in part because they serve to document the collective and

\footnotetext{
${ }^{4}$ Note that the pattern observed in sociology OLS estimates, where the estimated curve has an ever-increasing trajectory, corresponds to the presence of extremely successful articles. A similar pattern is observed in [24] for a subfield of research in economics: econometric methods. This provides further corroboration of the utility of QR estimates over OLS estimates.
}
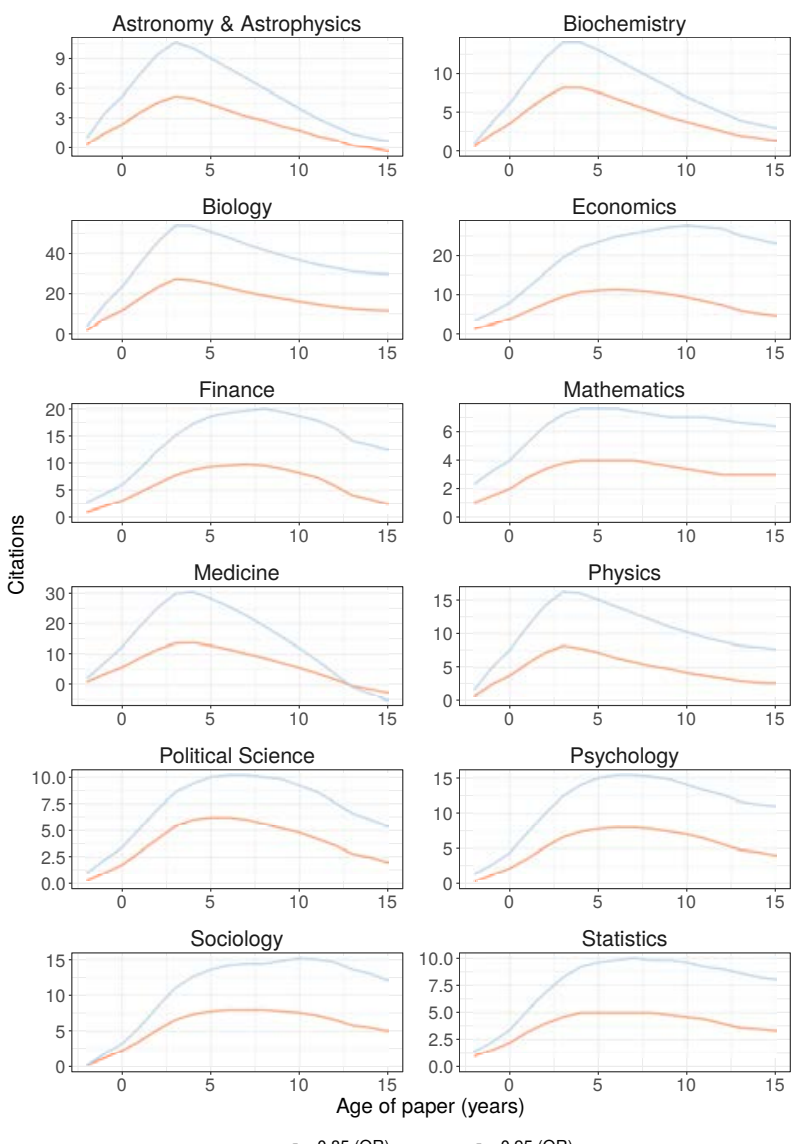

$\tau=0.85$ (QR) $\tau=0.95$ (QR)

Fig. 4: Estimated life cycles of research articles obtained by regression analysis across fields of research for highly successful articles. Estimates are presented for $\tau=0.85$ (estimated using QR) and for $\tau=0.95$ (estimated using QR). Values are smoothed using five-year centered moving averages. Note that the $y$-axis scales vary across sub-figures.

cumulative nature of knowledge production and in part because they are used as inputs for several influential evaluative metrics that are used to assess researchers' performance. Nevertheless, little effort has been devoted to understanding and quantifying how article citations evolve as articles grow older. In this study, we have focused on this issue.

We find evidence that points to the presence of life-cycle patterns in annual citations across a broad 
range of disciplines. In addition, these patterns tend to vary greatly across different fields of research. Social sciences such as economics, political science, and sociology exhibit longer life cycles, with annual citations of articles tending to reach a peak later on than in other disciplines and then declining after this peak quite gradually. Mathematics and statistics articles display a somewhat similar pattern, although the number of citations per year is much lower than in the case of the social sciences. In addition, in a number of fields, article citations are much more concentrated in the first years after publication. This is the case for astronomy \& astrophysics, biochemistry, biology, medicine and physics. As filtering articles by their age is a common practice when calculating evaluative metrics, these differences are by no mean neutral and should be taken into account when evaluating researchers or research institutions

Analyzing the reasons for the existence of these patterns is beyond the scope of this article. Of course, the size of the different disciplines influences the number of citations, as well as how much the discoveries made in each subject area transcend the fields of research which generate them [24, 27]. Nevertheless, a factor that is not commonly mentioned which might also affect these trends is time to publication. As an article is going to be cited by future articles, if those articles take a long time to be published, citations will be a long time in coming. Previous research suggests that time to publication varies markedly across fields [28]. For example, social science articles are known for having a long publication lead time. As stated in [29], a business/economics article usually takes 18 months to be published, while a physics article takes less than 10 months and an article on chemistry generally takes 6 months. Mathematics and statistics articles also take a long time to be published [30, 31], with mean times to publication in several journals being on the order of 20 months. We hope that future research will build on these findings by focusing on the different factors that shape citation patterns.

\section{Materials and Methods}

\section{Data collection}

As a first step in quantifying citation trends, we had to select which fields of research we would analyze. With the aim of covering a broad range of patterns in citation trends, we chose fields of research in the social sciences, life sciences, physical sciences, mathematical studies, and health studies. Specifically, we analyzed articles from the following disciplines: astronomy \& astrophysics, biochemistry, biology, economics, finance, mathematics, medicine, physics, political science, psychology, sociology, and statistics.

For each of these twelve fields of research, we chose five prestigious journals from which to sample articles. We restricted our selection to general research journals within each field or to sets of journals that, taken together, cover a wide range of topics within each area of research (as in the case of the physics journals that we selected). Our criteria for inclusion were that the journals had to be well known and be high-impact publications within each field and had to have high standards for acceptance. To ensure that the selected articles accurately represented the field under consideration, we chose to exclude multidisciplinary scientific journals such as Science, Nature and Proceedings of the National Academy of Sciences. To guide our search, we made use of publicly available journal rankings such as the Scimago Journal $\mathcal{E}$ Country Rank (www.scimagojr.com) and the Eigenfactor Score (www. eigenfactor.org). SI Appendix, Table S13 lists the selected journals by field of research.

For each of the 60 journals that we selected, we downloaded data on all the research articles published from 1980 up to 2004 from Thomson Reuters' Web of Science (WoS). The data included their titles, authors, publication dates, journal volumes, and total WoS citation counts. From this population of published research articles, we obtained a representative sample of articles using the following stratification scheme. First, for each field of research, 
we divided articles according to their publication date into five-year groups (one group for articles published in 1980-1984, another group for articles published in 1985-1989, and so on). Second, for every field of research and for every five-year period, we calculated the deciles of the distribution of total WoS citation counts and sampled without replacement $15 \%$ of all articles included in each decile. (For economics, finance, mathematics, political science, psychology, sociology, and statistics, we sampled $45 \%$ of all articles in each decile.) By following this sampling strategy, we ensured that our final sample would be representative in terms of fields of research, periods of time, and success as measured by total WoS citation counts. Additionally, by stratifying each five-year period, we made sure that our sampling strategy would not be affected by citation inflation.

Having constructed a representative sample of research articles, we gathered Google citations of each of them for every year starting from two years before publication up to late 2015. For this exercise, we followed a strategy similar to the one reported in [24]. Finally, for our analysis, we retained the articles published between 1985 and 2000. This left us with our final sample of 59,707 research articles.

\section{Acknowledgements}

The authors thank Lee Benham for valuable suggestions and comments.

\section{References}

[1] Rosenberg N (1974) Science, invention and economic growth. Econ J 84(333):90-108.

[2] Romer PM (1990) Endogenous technological change. J Polit Econ 98(5, Part 2):S71-S102.

[3] Fagerberg J, Srholec M, Verspagen B (2010) Innovation and economic development in Handbook of the Economics of Innovation, Volume 2, Handbook of the Economics of Innovation, eds. Hall BH, Rosenberg N. (North-Holland) Vol. 2, pp. 833-872.
[4] Yu G, Wang MY, Yu DR (2010) Characterizing knowledge diffusion of nanoscience \& nanotechnology by citation analysis. Scientometrics 84(1):81-97.

[5] Estabrooks CA, et al. (2008) The intellectual structure and substance of the knowledge utilization field: A longitudinal author co-citation analysis, 1945 to 2004 . Implement Sci 3-49(1):49.

[6] Park HW, Hong HD, Leydesdorff L (2005) A comparison of the knowledge-based innovation systems in the economies of south korea and the netherlands using triple helix indicators. Scientometrics 65(1):3-27.

[7] Catalini C, Lacetera N, Oettl A (2015) The incidence and role of negative citations in science. Proc Natl Acad Sci USA 112(45):13823-13826.

[8] Gibson J, Anderson DL, Tressler J (2014) Which journal rankings best explain academic salaries? evidence from the university of california. Econ Inq 52(4):13221340 .

[9] Ellison G (2013) How does the market use citation data? the hirsch index in economics. Am Econ J Appl Econ 5(3):63-90.

[10] Cole S, Cole JR (1967) Scientific output and recognition: A study in the operation of the reward system in science. Am Sociol Rev 32(3):377-390.

[11] Hazelkorn E (2015) Rankings and the reshaping of higher education: The battle for world-class excellence. (Springer).

[12] Abbott A, et al. (2010) Do metrics matter? Nature 465(7300):860-863.

[13] Hirsch JE (2005) An index to quantify an individual's scientific research output. Proc Natl Acad Sci USA 102(46):16569-16572.

[14] Bornmann L, Daniel HD (2005) Does the h-index for ranking of scientists really work? Scientometrics 65(3):391-392.

[15] Bornmann L, Daniel HD (2008) The state of $h$ index research. EMBO Rep 10(1):2-6.

[16] Fersht A (2009) The most influential journals: Impact factor and eigenfactor. Proc Natl Acad Sci USA 106(17):6883-6884.

[17] Eugene G (2006) The history and meaning of the journal impact factor. JAMA 295(1):90-93. 
[18] Seglen PO (1997) Why the impact factor of journals should not be used for evaluating research. BMJ 314(7079):498-513.

[19] Bornmann L, Daniel H (2008) What do citation counts measure? a review of studies on citing behavior. J Doc 64(1):45-80.

[20] Peters HPF, van Raan AFJ (1994) On determinants of citation scores: A case study in chemical engineering. J Am Soc Inf Sci 45(1):39-49.

[21] Radicchi F, Fortunato S, Castellano C (2008) Universality of citation distributions: Toward an objective measure of scientific impact. Proc Natl Acad Sci USA 105(45):17268-17272.

[22] Larsen PO, von Ins M (2010) The rate of growth in scientific publication and the decline in coverage provided by science citation index. Scientometrics 84(3):575-603.

[23] Neff BD, Olden JD (2010) Not so fast: Inflation in impact factors contributes to apparent improvements in journal quality. BioScience 60(6):455-459.

[24] Anauati V, Galiani S, Gálvez RH (2016) Quantifying the life cycle of scholarly articles across fields of economic research. Econ Inq 54(2):1339-1355. ECINDec-2014-12970.R2.

[25] Koenker R, Hallock KF (2001) Quantile regression. J Econ Perspect 15(4):143-156.

[26] Portnoy S, Koenker R (1997) The gaussian hare and the laplacian tortoise: computability of squared-error versus absolute-error estimators. Stat Sci 12(4):279300

[27] Van Noorden R, Maher B, Nuzzo R (2014) The top 100 papers. Nature 514(7524):550.

[28] Huisman J, Smits J (2017) Duration and quality of the peer review process: the author's perspective. Scientometrics pp. 1-18.

[29] Björk BC, Solomon D (2013) The publishing delay in scholarly peer-reviewed journals. J Informetr 7(4):914923.

[30] Carroll RJ (2001) Review times in statistical journals: Tilting at windmills? Biometrics 57(1):1-6.

[31] (2015) Backlog of mathematics research journals. Not AMS pp. 1266-1271. 


\section{Supporting Information}

Table S1: Regression Results Obtained for Astronomy \& Astrophysics

\begin{tabular}{|c|c|c|c|c|}
\hline & \multirow[b]{2}{*}{$\begin{array}{c}\text { Conditional Mean } \\
\text { (OLS) }\end{array}$} & \multicolumn{3}{|c|}{ Quantile Regression } \\
\hline & & $\tau=0.50$ & $\tau=0.85$ & $\tau=0.95$ \\
\hline Intercept & $0.64^{* * *}(0.18)$ & $0.00(0.00)$ & $1.00^{* * *}(0.03)$ & $3.00^{* * *}(0.25)$ \\
\hline$t=-2$ & $-0.71^{* * *}(0.09)$ & $-0.00(0.00)$ & $-1.00^{* * * *}(0.03)$ & $-3.00^{* * *}(0.25)$ \\
\hline$t=-1$ & $-0.82^{* * *}(0.09)$ & $-0.00(0.00)$ & $-1.00^{* * *}(0.03)$ & $-3.00^{* * *}(0.25)$ \\
\hline$t=1$ & $2.50^{* * *}(0.09)$ & $2.00^{* * *}(0.00)$ & $4.00^{* * *}(0.37)$ & $8.00^{* * *}(0.53)$ \\
\hline$t=2$ & $2.95^{* * *}(0.09)$ & $2.00^{* * *}(0.00)$ & $5.00^{* * *}(0.35)$ & $9.00^{* * *}(0.53)$ \\
\hline$t=3$ & $2.57^{* * *}(0.09)$ & $2.00^{* * *}(0.00)$ & $5.00^{* * *}(0.17)$ & $8.00^{* * *}(0.54)$ \\
\hline$t=4$ & $2.16^{* * *}(0.09)$ & $1.00^{* *}(0.43)$ & $4.00^{* * *}(0.08)$ & $7.00^{* * *}(0.53)$ \\
\hline$t=5$ & $1.74^{* * *}(0.09)$ & $1.00^{* * *}(0.00)$ & $3.00^{* * *}(0.43)$ & $6.00^{* * *}(0.49)$ \\
\hline$t=6$ & $1.35^{* * *}(0.09)$ & $1.00^{* * *}(0.00)$ & $3.00^{* * *}(0.04)$ & $5.00^{* * *}(0.55)$ \\
\hline $\mathrm{t}=7$ & $0.94^{* * * *}(0.10)$ & $1.00^{* * *}(0.00)$ & $2.00^{* * *}(0.18)$ & $4.00^{* * *}(0.52)$ \\
\hline$t=8$ & $0.61^{* * *}(0.10)$ & $1.00^{* * *}(0.00)$ & $2.00^{* * *}(0.34)$ & $3.00^{* * *}(0.48)$ \\
\hline$t=9$ & $0.31^{* * *}(0.10)$ & $0.00(0.18)$ & $1.00^{* * *}(0.25)$ & $2.00^{* * *}(0.42)$ \\
\hline$t=10$ & $0.05(0.10)$ & $0.00(0.00)$ & $1.00^{* * *}(0.29)$ & $1.00^{* *}(0.45)$ \\
\hline$t=11$ & $-0.19 *(0.10)$ & $-0.00(0.00)$ & $0.00(0.21)$ & $-0.00(0.43)$ \\
\hline$t=12$ & $-0.47^{* * *}(0.10)$ & $-0.00(0.00)$ & $-0.00(0.47)$ & $-1.00^{* *}(0.47)$ \\
\hline$t=13$ & $-0.67^{* * *}(0.10)$ & $-0.00(0.00)$ & $-1.00^{* * *}(0.28)$ & $-2.00^{* * *}(0.52)$ \\
\hline$t=14$ & $-0.86^{* * *}(0.10)$ & $-0.00(0.00)$ & $-1.00^{* * *}(0.18)$ & $-2.00^{* * *}(0.56)$ \\
\hline$t=15$ & $-1.07^{* * *}(0.11)$ & $-0.00(0.00)$ & $-2.00^{* * *}(0.50)$ & $-3.00^{* * *}(0.49)$ \\
\hline
\end{tabular}

The sample consists of 8,378 research articles published from 1985 to 2000 . The base category for the age of the paper is 0 and, for the year of citation, the base is 1985. All columns include controls for year-of-citation fixed effects $\left(\gamma_{y}(\tau)\right)$. Absolute values of stratified bootstrapped $t$ statistics are given in parentheses (1,000 iterations). Stratification is detailed in Materials and Methods. 
Table S2: Regression Results Obtained for Biochemistry

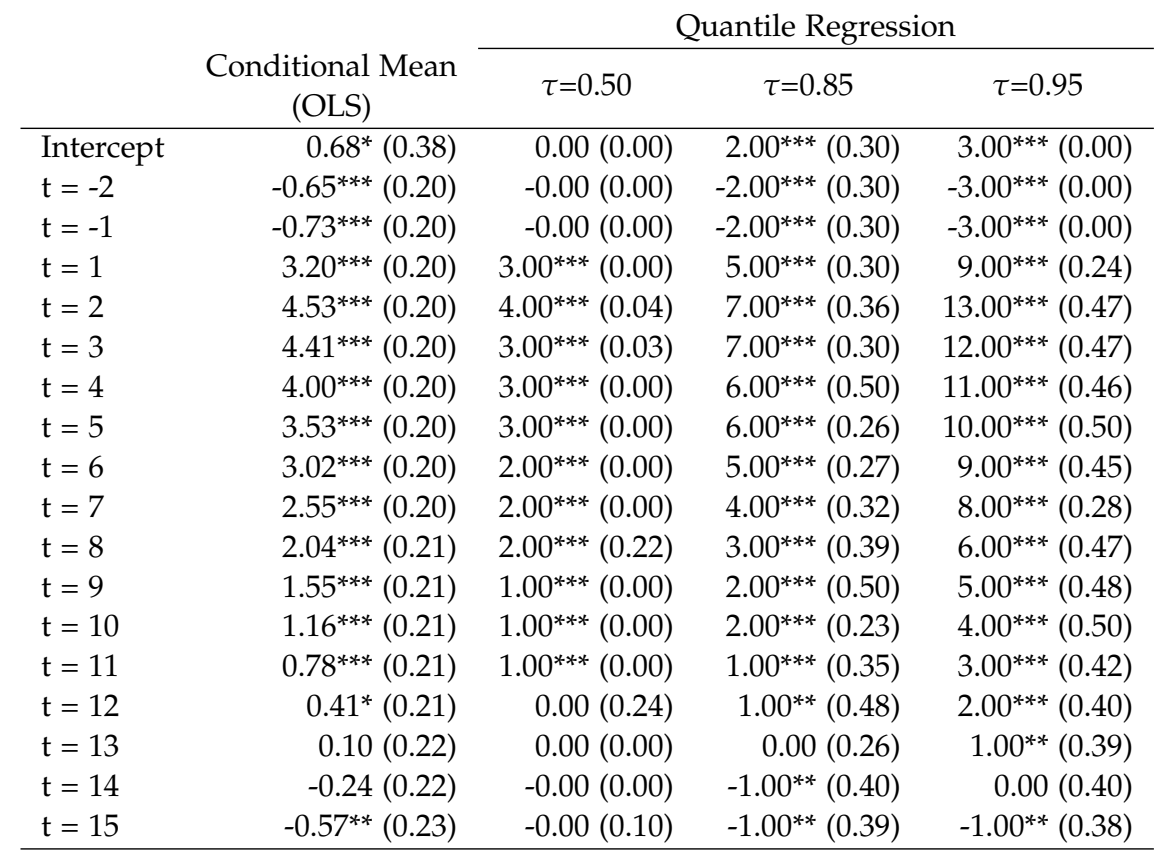

The sample consists of 18,429 research articles published from 1985 to 2000 . The base category for the age of the paper is 0 and, for the year of citation, the base is 1985. All columns include controls for year-of-citation fixed effects $\left(\gamma_{y}(\tau)\right)$. Absolute values of stratified bootstrapped $t$ statistics are given in parentheses (1,000 iterations). Stratification is detailed in Materials and Methods. 
Table S3: Regression Results Obtained for Biology

\begin{tabular}{|c|c|c|c|c|}
\hline & \multirow[b]{2}{*}{$\begin{array}{c}\text { Conditional Mean } \\
\text { (OLS) }\end{array}$} & \multicolumn{3}{|c|}{ Quantile Regression } \\
\hline & & $\tau=0.50$ & $\tau=0.85$ & $\tau=0.95$ \\
\hline Intercept & $2.12^{*}(1.27)$ & $1.00^{* * *}(0.20)$ & $5.00^{* * *}(0.47)$ & $11.00^{* * *}(0.66)$ \\
\hline$t=-2$ & $-2.32^{* * *}(0.66)$ & $-1.00^{* * *}(0.20)$ & $-5.00^{* * *}(0.47)$ & $-11.00^{* * *}(0.65)$ \\
\hline$t=-1$ & $-2.37^{* * *}(0.65)$ & $-1.00^{* * *}(0.20)$ & $-5.00^{* * *}(0.47)$ & $-11.00^{* * *}(0.65)$ \\
\hline$t=1$ & $8.82^{* * *}(0.64)$ & $2.00 * * *(0.23)$ & $20.00^{* * *}(0.93)$ & $37.00^{* * *}(2.24)$ \\
\hline$t=2$ & $12.02^{* * *}(0.65)$ & $3.00^{* * *}(0.53)$ & $24.00^{* * *}(1.22)$ & $48.00^{* * *}(2.40)$ \\
\hline$t=3$ & $12.04^{* * *}(0.65)$ & $4.00^{* * *}(0.32)$ & $25.00^{* * *}(1.24)$ & $45.00^{* * *}(2.85)$ \\
\hline$t=4$ & $11.55^{* * *}(0.66)$ & $4.00^{* * *}(0.39)$ & $23.00^{* * *}(1.11)$ & $43.00^{* * *}(3.32)$ \\
\hline$t=5$ & $10.77^{* * *}(0.66)$ & $4.00^{* * *}(0.54)$ & $20.00^{* * *}(1.15)$ & $41.00^{* * *}(2.91)$ \\
\hline$t=6$ & $9.73^{* * *}(0.67)$ & $3.00^{* * *}(0.46)$ & $17.00^{* * *}(1.18)$ & $36.00^{* * *}(3.15)$ \\
\hline$t=7$ & $8.80^{* * *}(0.67)$ & $3.00^{* * *}(0.23)$ & $16.00^{* * *}(1.05)$ & $33.00^{* * *}(2.48)$ \\
\hline$t=8$ & $8.12^{* * *}(0.68)$ & $3.00^{* * *}(0.49)$ & $14.00^{* * *}(1.09)$ & $31.00^{* * *}(3.08)$ \\
\hline$t=9$ & $7.33^{* * *}(0.68)$ & $2.00^{* * *}(0.47)$ & $13.00^{* * *}(1.23)$ & $26.00^{* * *}(2.83)$ \\
\hline$t=10$ & $6.71^{* * *}(0.69)$ & $2.00^{* * *}(0.27)$ & $11.00^{* * *}(1.13)$ & $27.00^{* * *}(3.15)$ \\
\hline$t=11$ & $6.00^{* * *}(0.70)$ & $2.00^{* * *}(0.23)$ & $10.00^{* * *}(1.01)$ & $23.00^{* * *}(3.17)$ \\
\hline$t=12$ & $5.34^{* * *}(0.71)$ & $2.00 * * *(0.53)$ & $8.00^{* * *}(1.10)$ & $21.00^{* * *}(3.19)$ \\
\hline$t=13$ & $4.92^{* * *}(0.72)$ & $1.00^{* * *}(0.31)$ & $7.00^{* * *}(1.13)$ & $20.00^{* * *}(3.52)$ \\
\hline$t=14$ & $4.64^{* * *}(0.73)$ & $1.00^{* * *}(0.24)$ & $7.00^{* * *}(0.99)$ & $18.00^{* * *}(3.45)$ \\
\hline$t=15$ & $4.27^{* * *}(0.75)$ & $1.00 *(0.50)$ & $6.00^{* * *}(1.07)$ & $18.00^{* * *}(3.68)$ \\
\hline
\end{tabular}

The sample consists of 2,284 research articles published from 1985 to 2000. The base category for the age of the paper is 0 and, for the year of citation, the base is 1985. All columns include controls for year-of-citation fixed effects $\left(\gamma_{y}(\tau)\right)$. Absolute values of stratified bootstrapped $t$ statistics are given in parentheses (1,000 iterations). Stratification is detailed in Materials and Methods. 
Table S4: Regression Results Obtained for Economics

\begin{tabular}{|c|c|c|c|c|}
\hline & \multirow[b]{2}{*}{$\begin{array}{c}\text { Conditional Mean } \\
\text { (OLS) }\end{array}$} & \multicolumn{3}{|c|}{ Quantile Regression } \\
\hline & & $\tau=0.50$ & $\tau=0.85$ & $\tau=0.95$ \\
\hline Intercept & $1.48(1.61)$ & $1.00^{* * *}(0.00)$ & $3.00^{* * *}(0.35)$ & $6.00^{* * *}(0.56)$ \\
\hline$t=-2$ & $-1.34(1.00)$ & $-1.00^{* * *}(0.00)$ & $-3.00^{* * *}(0.36)$ & $-5.00^{* * *}(0.51)$ \\
\hline$t=-1$ & $-1.00(0.98)$ & $-1.00^{* * *}(0.00)$ & $-2.00^{* * *}(0.35)$ & $-3.00^{* * *}(0.60)$ \\
\hline$t=1$ & $2.14^{* *}(0.97)$ & $1.00^{* * *}(0.09)$ & $3.00^{* * *}(0.47)$ & $6.00^{* * *}(0.88)$ \\
\hline$t=2$ & $3.83^{* * *}(0.98)$ & $2.00^{* * *}(0.08)$ & $6.00^{* * *}(0.55)$ & $12.00^{* * *}(1.24)$ \\
\hline$t=3$ & $4.50^{* * *}(0.99)$ & $2.00^{* * *}(0.32)$ & $7.00^{* * *}(0.59)$ & $14.00^{* * *}(1.61)$ \\
\hline$t=4$ & $5.04^{* * *}(0.99)$ & $3.00^{* * *}(0.41)$ & $8.00^{* * *}(0.68)$ & $16.00^{* * *}(1.39)$ \\
\hline$t=5$ & $5.35^{* * *}(1.00)$ & $2.00^{* * *}(0.44)$ & $9.00^{* * *}(0.77)$ & $19.00^{* * *}(1.96)$ \\
\hline$t=6$ & $5.52^{* * *}(1.00)$ & $2.00^{* * *}(0.46)$ & $9.00^{* * *}(0.83)$ & $19.00^{* * *}(2.04)$ \\
\hline$t=7$ & $5.48^{* * *}(1.01)$ & $2.00^{* * *}(0.24)$ & $8.00^{* * *}(0.96)$ & $19.00^{* * *}(2.70)$ \\
\hline$t=8$ & $5.49^{* * *}(1.02)$ & $2.00^{* * *}(0.14)$ & $8.00^{* * *}(0.95)$ & $21.00^{* * *}(2.44)$ \\
\hline$t=9$ & $5.42^{* * *}(1.03)$ & $1.00^{* *}(0.50)$ & $7.00^{* * *}(1.01)$ & $20.00^{* * *}(3.42)$ \\
\hline$t=10$ & $4.93^{* * *}(1.04)$ & $1.00^{* * *}(0.31)$ & $7.00^{* * *}(1.23)$ & $23.00^{* * *}(3.97)$ \\
\hline$t=11$ & $4.53^{* * *}(1.05)$ & $0.00(0.48)$ & $6.00^{* * *}(1.12)$ & $23.00^{* * *}(4.19)$ \\
\hline$t=12$ & $3.91^{* * *}(1.06)$ & $0.00(0.25)$ & $4.00^{* * *}(1.32)$ & $21.00^{* * *}(4.13)$ \\
\hline$t=13$ & $3.09^{* * *}(1.07)$ & $-1.00^{* *}(0.49)$ & $3.00^{* *}(1.38)$ & $19.00^{* * *}(4.61)$ \\
\hline$t=14$ & $2.59^{* *}(1.09)$ & $-2.00^{* * *}(0.44)$ & $2.00(1.48)$ & $18.00^{* * *}(5.27)$ \\
\hline$t=15$ & $2.24^{* *}(1.11)$ & $-2.00^{* * *}(0.39)$ & $0.00(1.65)$ & $14.00^{* *}(5.38)$ \\
\hline
\end{tabular}

The sample consists of 2,471 research articles published from 1985 to 2000. The base category for the age of the paper is 0 and, for the year of citation, the base is 1985. All columns include controls for year-of-citation fixed effects $\left(\gamma_{y}(\tau)\right)$. Absolute values of stratified bootstrapped $\mathrm{t}$ statistics are given in parentheses (1,000 iterations). Stratification is detailed in Materials and Methods. 
Table S5: Regression Results Obtained for Finance

\begin{tabular}{lrrrr} 
& & \multicolumn{3}{c}{ Quantile Regression } \\
\cline { 3 - 5 } & Conditional Mean & \multirow{2}{*}{$\tau=0.50$} & $\tau=0.85$ & $\tau=0.95$ \\
\hline Intercept & $1.21(2.21)$ & $0.00(0.33)$ & $2.00^{* * *}(0.47)$ & $5.00^{* * *}(0.43)$ \\
$\mathrm{t}=-2$ & $-1.07(1.18)$ & $-0.00(0.33)$ & $-2.00^{* * *}(0.42)$ & $-4.00^{* * *}(0.43)$ \\
$\mathrm{t}=-1$ & $-0.85(1.16)$ & $-0.00(0.33)$ & $-1.00^{* *}(0.44)$ & $-3.00^{* * *}(0.54)$ \\
$\mathrm{t}=1$ & $1.49(1.16)$ & $1.00^{* *}(0.46)$ & $3.00^{* * *}(0.51)$ & $4.00^{* * *}(0.73)$ \\
$\mathrm{t}=2$ & $2.85^{* *}(1.17)$ & $2.00^{* * *}(0.33)$ & $5.00^{* * *}(0.56)$ & $8.00^{* * *}(0.94)$ \\
$\mathrm{t}=3$ & $3.82^{* * *}(1.17)$ & $3.00^{* * *}(0.40)$ & $6.00^{* * *}(0.72)$ & $11.00^{* * * *}(1.24)$ \\
$\mathrm{t}=4$ & $4.27^{* * *}(1.18)$ & $3.00^{* * *}(0.34)$ & $7.00^{* * *}(0.71)$ & $13.00^{* * *}(1.59)$ \\
$\mathrm{t}=5$ & $4.43^{* * *}(1.19)$ & $3.00^{* * *}(0.33)$ & $8.00^{* * *}(0.94)$ & $14.00^{* * *}(1.91)$ \\
$\mathrm{t}=6$ & $4.70^{* * *}(1.20)$ & $3.00^{* * *}(0.37)$ & $8.00^{* * *}(0.92)$ & $15.00^{* * *}(1.90)$ \\
$\mathrm{t}=7$ & $4.43^{* * *}(1.21)$ & $3.00^{* * *}(0.51)$ & $8.00^{* * *}(0.99)$ & $15.00^{* * *}(2.17)$ \\
$\mathrm{t}=8$ & $4.18^{* * *}(1.22)$ & $3.00^{* * *}(0.51)$ & $7.00^{* * *}(0.94)$ & $14.00^{* * *}(2.29)$ \\
$\mathrm{t}=9$ & $3.61^{* * *}(1.23)$ & $2.00^{* * *}(0.40)$ & $8.00^{* * *}(1.15)$ & $15.00^{* * * *}(2.53)$ \\
$\mathrm{t}=10$ & $3.31^{* * *}(1.24)$ & $2.00^{* * *}(0.54)$ & $7.00^{* * *}(1.13)$ & $16.00^{* * * *}(3.78)$ \\
$\mathrm{t}=11$ & $2.45^{*}(1.25)$ & $1.00^{* *}(0.48)$ & $5.00^{* * *}(1.01)$ & $12.00^{* * *}(3.16)$ \\
$\mathrm{t}=12$ & $1.23(1.27)$ & $1.00^{* *}(0.49)$ & $4.00^{* * *}(1.30)$ & $11.00^{* *}(4.36)$ \\
$\mathrm{t}=13$ & $0.32(1.28)$ & $-0.00(0.47)$ & $3.00^{*}(1.54)$ & $10.00^{* *}(4.55)$ \\
$\mathrm{t}=14$ & $-0.46(1.31)$ & $-0.00(0.54)$ & $-0.00(1.84)$ & $8.00(5.13)$ \\
$\mathrm{t}=15$ & $-1.97(1.34)$ & $-1.00^{* *}(0.49)$ & $-2.00(1.77)$ & $4.00(5.73)$ \\
\hline
\end{tabular}

The sample consists of 1,642 research articles published from 1985 to 2000 . The base category for the age of the paper is 0 and, for the year of citation, the base is 1985. All columns include controls for year-of-citation fixed effects $\left(\gamma_{y}(\tau)\right)$. Absolute values of stratified bootstrapped $t$ statistics are given in parentheses (1,000 iterations). Stratification is detailed in Materials and Methods. 
Table S6: Regression Results Obtained for Mathematics

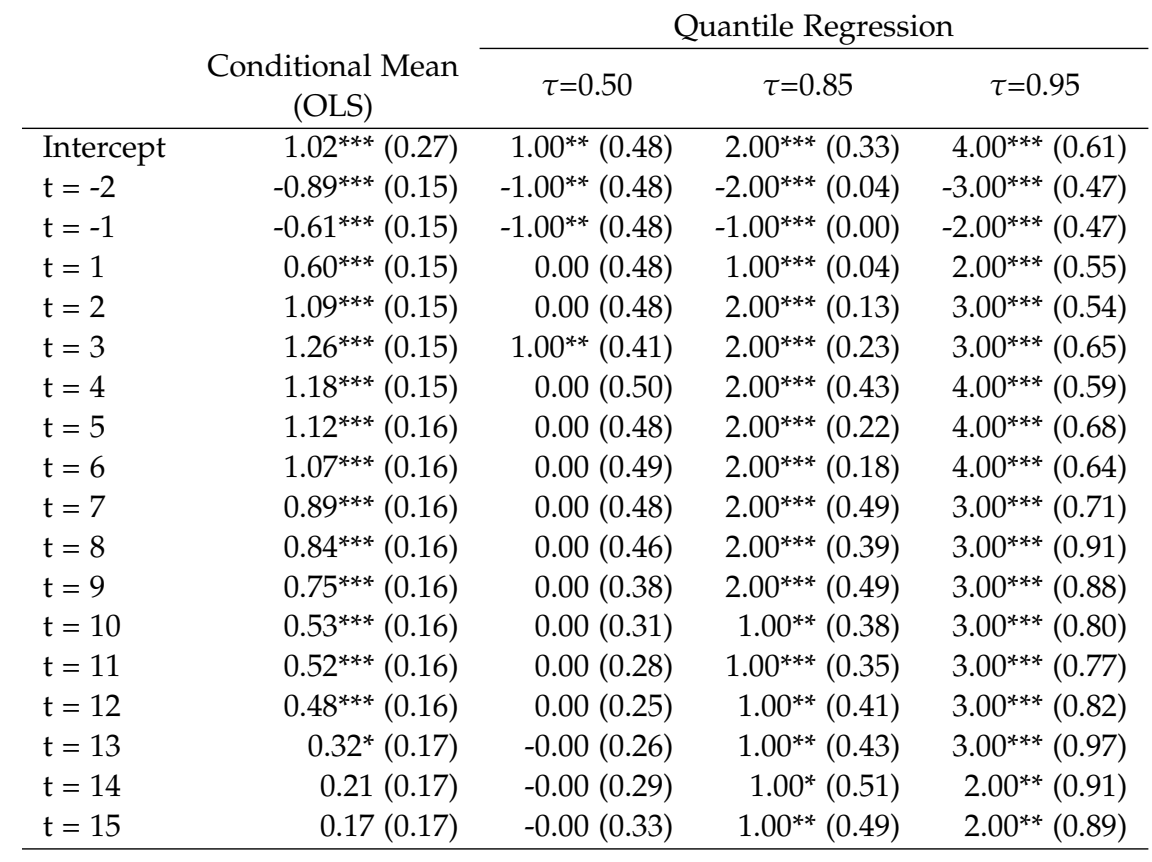

The sample consists of 1,609 research articles published from 1985 to 2000. The base category for the age of the paper is 0 and, for the year of citation, the base is 1985. All columns include controls for year-of-citation fixed effects $\left(\gamma_{y}(\tau)\right)$. Absolute values of stratified bootstrapped $t$ statistics are given in parentheses (1,000 iterations). Stratification is detailed in Materials and Methods. 
Table S7: Regression Results Obtained for Medicine

\begin{tabular}{|c|c|c|c|c|}
\hline & \multirow[b]{2}{*}{$\begin{array}{c}\text { Conditional Mean } \\
\text { (OLS) }\end{array}$} & \multicolumn{3}{|c|}{ Quantile Regression } \\
\hline & & $\tau=0.50$ & $\tau=0.85$ & $\tau=0.95$ \\
\hline Intercept & $1.33^{* *}(0.62)$ & $0.00(0.16)$ & $3.00^{* * *}(0.00)$ & $6.00^{* * *}(0.47)$ \\
\hline$t=-2$ & $-1.38^{* * *}(0.39)$ & $-0.00(0.16)$ & $-3.00^{* * *}(0.00)$ & $-6.00^{* * *}(0.47)$ \\
\hline$t=-1$ & $-1.55^{* * *}(0.38)$ & $-0.00(0.16)$ & $-3.00^{* * *}(0.00)$ & $-6.00^{* * *}(0.47)$ \\
\hline$t=1$ & $4.67^{* * *}(0.38)$ & $2.00^{* * *}(0.51)$ & $8.00^{* * *}(0.38)$ & $17.00^{* * *}(1.17)$ \\
\hline$t=2$ & $6.97^{* * *}(0.38)$ & $3.00^{* * *}(0.51)$ & $12.00^{* * *}(0.63)$ & $27.00^{* * *}(1.46)$ \\
\hline$t=3$ & $7.08^{* * *}(0.38)$ & $3.00^{* * *}(0.40)$ & $12.00^{* * *}(0.61)$ & $27.00^{* * *}(1.41)$ \\
\hline$t=4$ & $6.56^{* * *}(0.38)$ & $3.00^{* * *}(0.16)$ & $11.00^{* * *}(0.54)$ & $25.00^{* * *}(1.37)$ \\
\hline$t=5$ & $5.92^{* * *}(0.39)$ & $3.00^{* * *}(0.25)$ & $10.00^{* * *}(0.66)$ & $23.00^{* * *}(1.42)$ \\
\hline$t=6$ & $5.22^{* * *}(0.39)$ & $2.69^{* * *}(0.49)$ & $9.00^{* * *}(0.69)$ & $20.00^{* * *}(1.80)$ \\
\hline$t=7$ & $4.33^{* * *}(0.39)$ & $2.00^{* * *}(0.19)$ & $7.00^{* * *}(0.63)$ & $16.00^{* * *}(1.35)$ \\
\hline$t=8$ & $3.53^{* * *}(0.40)$ & $2.00^{* * *}(0.16)$ & $6.00^{* * *}(0.53)$ & $14.00^{* * *}(1.70)$ \\
\hline$t=9$ & $2.49^{* * *}(0.40)$ & $2.00^{* * *}(0.46)$ & $4.00^{* * *}(0.50)$ & $10.00^{* * *}(1.62)$ \\
\hline$t=10$ & $1.43^{* * *}(0.40)$ & $1.00^{* * *}(0.24)$ & $3.00^{* * *}(0.56)$ & $6.00^{* * *}(1.27)$ \\
\hline $\mathrm{t}=11$ & $0.45(0.40)$ & $1.00^{* * *}(0.16)$ & $1.00(0.61)$ & $2.00 *(1.18)$ \\
\hline$t=12$ & $-0.50(0.41)$ & $1.00^{* * *}(0.16)$ & $-1.00^{*}(0.55)$ & $-2.00(1.33)$ \\
\hline$t=13$ & $-1.60^{* * *}(0.41)$ & $0.00(0.49)$ & $-3.00^{* * *}(0.53)$ & $-6.00^{* * *}(1.47)$ \\
\hline$t=14$ & $-2.64^{* * *}(0.42)$ & $-0.00(0.20)$ & $-6.00^{* * *}(0.58)$ & $-12.00^{* * *}(1.35)$ \\
\hline$t=15$ & $-3.99^{* * *}(0.43)$ & $-0.00(0.26)$ & $-8.00^{* * *}(0.60)$ & $-16.00^{* * *}(1.45)$ \\
\hline
\end{tabular}

The sample consists of 5,234 research articles published from 1985 to 2000. The base category for the age of the paper is 0 and, for the year of citation, the base is 1985. All columns include controls for year-of-citation fixed effects $\left(\gamma_{y}(\tau)\right)$. Absolute values of stratified bootstrapped $\mathrm{t}$ statistics are given in parentheses (1,000 iterations). Stratification is detailed in Materials and Methods. 
Table S8: Regression Results Obtained for Physics

\begin{tabular}{lrrrr} 
& & \multicolumn{3}{c}{ Quantile Regression } \\
\cline { 3 - 5 } & Conditional Mean & \multirow{2}{*}{$\tau=0.50$} & $\tau=0.85$ & $\tau=0.95$ \\
\hline Intercept & $1.31^{* * *}(0.23)$ & $0.00(0.00)$ & $2.00^{* * *}(0.08)$ & $5.00^{* * *}(0.23)$ \\
$\mathrm{t}=-2$ & $-1.27^{* * *}(0.11)$ & $-0.00(0.00)$ & $-2.00^{* * *}(0.08)$ & $-5.00^{* * *}(0.23)$ \\
$\mathrm{t}=-1$ & $-1.25^{* * *}(0.10)$ & $-0.00(0.00)$ & $-2.00^{* * *}(0.08)$ & $-5.00^{* * *}(0.23)$ \\
$\mathrm{t}=1$ & $3.16^{* * *}(0.10)$ & $2.00^{* * *}(0.00)$ & $6.00^{* * *}(0.08)$ & $10.00^{* * *}(0.47)$ \\
$\mathrm{t}=2$ & $3.84^{* * *}(0.11)$ & $3.00^{* * *}(0.00)$ & $7.00^{* * *}(0.33)$ & $13.00^{* * *}(0.56)$ \\
$\mathrm{t}=3$ & $3.46^{* * *}(0.11)$ & $2.00^{* * *}(0.00)$ & $7.00^{* * *}(0.44)$ & $12.00^{* * * *}(0.51)$ \\
$\mathrm{t}=4$ & $3.09^{* * *}(0.11)$ & $2.00^{* * *}(0.00)$ & $6.00^{* * *}(0.13)$ & $11.00^{* * *}(0.44)$ \\
$\mathrm{t}=5$ & $2.69^{* * *}(0.11)$ & $2.00^{* * *}(0.00)$ & $5.00^{* * *}(0.34)$ & $10.00^{* * *}(0.49)$ \\
$\mathrm{t}=6$ & $2.34^{* * *}(0.11)$ & $2.00^{* * *}(0.00)$ & $4.00^{* * *}(0.50)$ & $9.00^{* * *}(0.52)$ \\
$\mathrm{t}=7$ & $1.99^{* * *}(0.11)$ & $1.00^{* * *}(0.00)$ & $4.00^{* * *}(0.13)$ & $8.00^{* * *}(0.54)$ \\
$\mathrm{t}=8$ & $1.69^{* * *}(0.11)$ & $1.00^{* * *}(0.00)$ & $3.00^{* * *}(0.34)$ & $7.00^{* * *}(0.55)$ \\
$\mathrm{t}=9$ & $1.45^{* * *}(0.11)$ & $1.00^{* * *}(0.00)$ & $3.00^{* * *}(0.31)$ & $6.00^{* * * *}(0.55)$ \\
$\mathrm{t}=10$ & $1.20^{* * *}(0.11)$ & $1.00^{* * *}(0.00)$ & $2.00^{* * *}(0.31)$ & $5.00^{* * * *}(0.47)$ \\
$\mathrm{t}=11$ & $1.05^{* * *}(0.11)$ & $1.00^{* * *}(0.00)$ & $2.00^{* * *}(0.24)$ & $4.00^{* * *}(0.47)$ \\
$\mathrm{t}=12$ & $0.88^{* * *}(0.11)$ & $1.00^{* * *}(0.00)$ & $1.00^{* *}(0.46)$ & $4.00^{* * *}(0.56)$ \\
$\mathrm{t}=13$ & $0.72^{* * *}(0.12)$ & $1.00^{* * *}(0.00)$ & $1.00^{* * *}(0.29)$ & $3.00^{* * * *}(0.53)$ \\
$\mathrm{t}=14$ & $0.64^{* * *}(0.12)$ & $1.00^{* * *}(0.00)$ & $1.00^{* * *}(0.27)$ & $3.00^{* * * *}(0.60)$ \\
$\mathrm{t}=15$ & $0.52^{* * *}(0.12)$ & $1.00^{* * *}(0.00)$ & $0.00(0.50)$ & $2.00^{* * * *}(0.54)$ \\
\hline
\end{tabular}

The sample consists of 12,599 research articles published from 1985 to 2000 . The base category for the age of the paper is 0 and, for the year of citation, the base is 1985. All columns include controls for year-of-citation fixed effects $\left(\gamma_{y}(\tau)\right)$. Absolute values of stratified bootstrapped $t$ statistics are given in parentheses (1,000 iterations). Stratification is detailed in Materials and Methods. 
Table S9: Regression Results Obtained for Political Science

\begin{tabular}{lrrrr} 
& & \multicolumn{3}{c}{ Quantile Regression } \\
\cline { 3 - 5 } & Conditional Mean & \multirow{2}{*}{$\tau=0.50$} & $\tau=0.85$ & $\tau=0.95$ \\
\hline Intercept & $0.27(0.85)$ & $0.00(0.00)$ & $1.00^{* * *}(0.00)$ & $2.00^{* * *}(0.42)$ \\
$\mathrm{t}=-2$ & $0.05(0.48)$ & $-0.00(0.00)$ & $-1.00^{* * *}(0.00)$ & $-2.00^{* * *}(0.24)$ \\
$\mathrm{t}=-1$ & $-0.33(0.47)$ & $-0.00(0.00)$ & $-1.00^{* * *}(0.00)$ & $-1.00^{* * *}(0.34)$ \\
$\mathrm{t}=1$ & $1.13^{* *}(0.47)$ & $1.00^{* * *}(0.00)$ & $2.00^{* * *}(0.13)$ & $4.00^{* * *}(0.54)$ \\
$\mathrm{t}=2$ & $2.20^{* * *}(0.47)$ & $2.00^{* * *}(0.07)$ & $4.00^{* * *}(0.36)$ & $6.00^{* * *}(0.71)$ \\
$\mathrm{t}=3$ & $2.69^{* * *}(0.48)$ & $2.00^{* * *}(0.03)$ & $5.00^{* * *}(0.45)$ & $7.00^{* * *}(0.61)$ \\
$\mathrm{t}=4$ & $2.83^{* * *}(0.48)$ & $2.00^{* * *}(0.00)$ & $5.00^{* * *}(0.52)$ & $8.00^{* * *}(1.13)$ \\
$\mathrm{t}=5$ & $2.75^{* * *}(0.48)$ & $2.00^{* * *}(0.03)$ & $6.00^{* * *}(0.52)$ & $8.00^{* * *}(0.77)$ \\
$\mathrm{t}=6$ & $2.84^{* * *}(0.48)$ & $2.00^{* * *}(0.09)$ & $5.00^{* * *}(0.50)$ & $8.00^{* * *}(0.92)$ \\
$\mathrm{t}=7$ & $2.62^{* * *}(0.49)$ & $2.00^{* * *}(0.12)$ & $5.00^{* * *}(0.50)$ & $9.00^{* * *}(0.86)$ \\
$\mathrm{t}=8$ & $2.35^{* * *}(0.49)$ & $1.00^{* *}(0.49)$ & $5.00^{* * *}(0.55)$ & $8.00^{* * * *}(0.87)$ \\
$\mathrm{t}=9$ & $2.03^{* * *}(0.50)$ & $1.00^{* * *}(0.35)$ & $4.00^{* * *}(0.62)$ & $8.00^{* * * *}(0.97)$ \\
$\mathrm{t}=10$ & $1.76^{* * *}(0.50)$ & $1.00^{* *}(0.41)$ & $4.00^{* * *}(0.62)$ & $7.00^{* * *}(1.21)$ \\
$\mathrm{t}=11$ & $1.45^{* * *}(0.51)$ & $1.00^{* * *}(0.26)$ & $3.00^{* * *}(0.68)$ & $7.00^{* * *}(1.20)$ \\
$\mathrm{t}=12$ & $0.94^{*}(0.51)$ & $0.00(0.49)$ & $3.00^{* * *}(0.67)$ & $6.00^{* * *}(1.63)$ \\
$\mathrm{t}=13$ & $0.40(0.52)$ & $0.00(0.39)$ & $2.00^{* * *}(0.63)$ & $5.00^{* *}(1.89)$ \\
$\mathrm{t}=14$ & $-0.23(0.53)$ & $-0.00(0.44)$ & $1.00(0.74)$ & $3.00^{*}(1.77)$ \\
$\mathrm{t}=15$ & $-0.59(0.54)$ & $-1.00^{* *}(0.48)$ & $0.00(0.80)$ & $2.00(2.11)$ \\
\hline
\end{tabular}

The sample consists of 1,266 research articles published from 1985 to 2000 . The base category for the age of the paper is 0 and, for the year of citation, the base is 1985. All columns include controls for year-of-citation fixed effects $\left(\gamma_{y}(\tau)\right)$. Absolute values of stratified bootstrapped $t$ statistics are given in parentheses (1,000 iterations). Stratification is detailed in Materials and Methods. 
Table S10: Regression Results Obtained for Psychology

\begin{tabular}{|c|c|c|c|c|}
\hline & \multirow[b]{2}{*}{$\begin{array}{l}\text { Conditional Mean } \\
\text { (OLS) }\end{array}$} & \multicolumn{3}{|c|}{ Quantile Regression } \\
\hline & & $\tau=0.50$ & $\tau=0.85$ & $\tau=0.95$ \\
\hline Intercept & $0.67(0.64)$ & $0.00(0.00)$ & $1.00^{* *}(0.46)$ & $3.00^{* * *}(0.52)$ \\
\hline$t=-2$ & $-0.55^{*}(0.31)$ & $-0.00(0.00)$ & $-1.00^{* *}(0.46)$ & $-3.00^{* * *}(0.21)$ \\
\hline$t=-1$ & $-0.50(0.30)$ & $-0.00(0.00)$ & $-1.00^{* *}(0.46)$ & $-2.00^{* * *}(0.20)$ \\
\hline$t=1$ & $1.56^{* * *}(0.30)$ & $1.00^{* * *}(0.05)$ & $3.00^{* * *}(0.46)$ & $4.00^{* * *}(0.57)$ \\
\hline$t=2$ & $3.10^{* * *}(0.31)$ & $2.00^{* * *}(0.49)$ & $5.00^{* * *}(0.60)$ & $8.00^{* * *}(0.86)$ \\
\hline$t=3$ & $3.70^{* * *}(0.31)$ & $3.00^{* * *}(0.05)$ & $6.00^{* * *}(0.60)$ & $11.00^{* * *}(0.92)$ \\
\hline$t=4$ & $4.04^{* * *}(0.31)$ & $3.00^{* * *}(0.03)$ & $7.00^{* * *}(0.58)$ & $12.00^{* * *}(0.88)$ \\
\hline$t=5$ & $4.14^{* * *}(0.31)$ & $3.00^{* * *}(0.03)$ & $7.00^{* * *}(0.60)$ & $12.00^{* * *}(1.10)$ \\
\hline$t=6$ & $4.19^{* * *}(0.32)$ & $3.00^{* * *}(0.00)$ & $7.00^{* * *}(0.62)$ & $12.00^{* * *}(1.01)$ \\
\hline$t=7$ & $4.20^{* * *}(0.32)$ & $3.00^{* * *}(0.42)$ & $7.00^{* * *}(0.59)$ & $13.00^{* * *}(1.11)$ \\
\hline$t=8$ & $4.01^{* * *}(0.32)$ & $2.00^{* * *}(0.29)$ & $7.00^{* * *}(0.62)$ & $13.00^{* * *}(1.09)$ \\
\hline$t=9$ & $3.83^{* * *}(0.32)$ & $2.00^{* * *}(0.08)$ & $7.00^{* * *}(0.68)$ & $12.00^{* * *}(1.26)$ \\
\hline$t=10$ & $3.42^{* * *}(0.33)$ & $2.00^{* * *}(0.14)$ & $6.00^{* * *}(0.65)$ & $11.00^{* * *}(1.48)$ \\
\hline$t=11$ & $3.05^{* * *}(0.33)$ & $2.00^{* * *}(0.49)$ & $5.00^{* * *}(0.62)$ & $10.00^{* * *}(2.10)$ \\
\hline$t=12$ & $2.91^{* * *}(0.34)$ & $1.00^{* * *}(0.11)$ & $5.00^{* * *}(0.65)$ & $9.00^{* * *}(1.56)$ \\
\hline$t=13$ & $2.46^{* * *}(0.34)$ & $1.00^{* * *}(0.23)$ & $4.00^{* * *}(0.66)$ & $9.00^{* * *}(1.93)$ \\
\hline$t=14$ & $2.03^{* * *}(0.35)$ & $1.00^{* *}(0.49)$ & $3.00^{* * *}(0.68)$ & $9.00^{* * *}(2.11)$ \\
\hline$t=15$ & $1.62^{* * *}(0.36)$ & $-0.00(0.09)$ & $2.00^{* * *}(0.69)$ & $6.00^{* * *}(2.23)$ \\
\hline
\end{tabular}

The sample consists of 2,044 research articles published from 1985 to 2000. The base category for the age of the paper is 0 and, for the year of citation, the base is 1985. All columns include controls for year-of-citation fixed effects $\left(\gamma_{y}(\tau)\right)$. Absolute values of stratified bootstrapped $t$ statistics are given in parentheses (1,000 iterations). Stratification is detailed in Materials and Methods. 
Table S11: Regression Results Obtained for Sociology

\begin{tabular}{lrrrr} 
& & \multicolumn{3}{c}{ Quantile Regression } \\
\cline { 3 - 5 } & Conditional Mean & \multirow{2}{*}{$\tau=0.50$} & $\tau=0.85$ & $\tau=0.95$ \\
\hline Intercept & $0.44(1.70)$ & $0.00(0.00)$ & $1.00^{* * *}(0.00)$ & $1.00^{* *}(0.42)$ \\
$\mathrm{t}=-2$ & $-0.37(0.99)$ & $-0.00(0.00)$ & $-1.00^{* * *}(0.00)$ & $-1.00^{* *}(0.42)$ \\
$\mathrm{t}=-1$ & $-0.37(0.97)$ & $-0.00(0.00)$ & $-1.00^{* * *}(0.00)$ & $-1.00^{* *}(0.50)$ \\
$\mathrm{t}=1$ & $1.45(0.97)$ & $1.00^{* * *}(0.00)$ & $3.00^{* * *}(0.20)$ & $5.00^{* * *}(0.54)$ \\
$\mathrm{t}=2$ & $2.80^{* * *}(0.98)$ & $2.00^{* * *}(0.17)$ & $5.00^{* * *}(0.39)$ & $8.00^{* * *}(0.62)$ \\
$\mathrm{t}=3$ & $3.55^{* * *}(0.98)$ & $3.00^{* * *}(0.38)$ & $6.00^{* * *}(0.57)$ & $11.00^{* * * *}(0.91)$ \\
$\mathrm{t}=4$ & $4.03^{* * *}(0.99)$ & $3.00^{* * *}(0.30)$ & $7.00^{* * *}(0.45)$ & $13.00^{* * *}(0.91)$ \\
$\mathrm{t}=5$ & $4.42^{* * *}(1.00)$ & $3.00^{* * *}(0.05)$ & $7.00^{* * *}(0.64)$ & $13.00^{* * *}(1.12)$ \\
$\mathrm{t}=6$ & $4.43^{* * *}(1.00)$ & $3.00^{* * *}(0.18)$ & $7.00^{* * *}(0.60)$ & $13.00^{* * *}(1.18)$ \\
$\mathrm{t}=7$ & $4.48^{* * *}(1.01)$ & $3.00^{* * *}(0.39)$ & $7.00^{* * *}(0.62)$ & $13.00^{* * *}(1.61)$ \\
$\mathrm{t}=8$ & $4.86^{* * *}(1.02)$ & $3.00^{* * *}(0.37)$ & $7.00^{* * *}(0.74)$ & $14.00^{* * *}(1.41)$ \\
$\mathrm{t}=9$ & $5.06^{* * *}(1.03)$ & $2.00^{* * *}(0.50)$ & $7.00^{* * *}(0.82)$ & $14.00^{* * *}(2.13)$ \\
$\mathrm{t}=10$ & $5.21^{* * *}(1.04)$ & $2.00^{* * *}(0.50)$ & $7.00^{* * *}(0.76)$ & $13.00^{* * *}(1.61)$ \\
$\mathrm{t}=11$ & $5.41^{* * *}(1.05)$ & $2.00^{* * *}(0.28)$ & $6.00^{* * *}(0.85)$ & $15.00^{* * *}(2.46)$ \\
$\mathrm{t}=12$ & $5.44^{* * *}(1.06)$ & $2.00^{* * *}(0.44)$ & $6.00^{* * *}(0.84)$ & $15.00^{* * *}(2.83)$ \\
$\mathrm{t}=13$ & $5.58^{* * *}(1.08)$ & $2.00^{* * *}(0.49)$ & $5.00^{* * *}(0.84)$ & $13.00^{* * *}(3.01)$ \\
$\mathrm{t}=14$ & $5.73^{* * *}(1.09)$ & $1.00^{* *}(0.45)$ & $4.00^{* * *}(0.94)$ & $12.00^{* * *}(3.44)$ \\
$\mathrm{t}=15$ & $5.80^{* * *}(1.12)$ & $1.00^{* *}(0.43)$ & $3.00^{* * *}(1.01)$ & $8.00^{* *}(3.55)$ \\
\hline
\end{tabular}

The sample consists of 1,167 research articles published from 1985 to 2000. The base category for the age of the paper is 0 and, for the year of citation, the base is 1985. All columns include controls for year-of-citation fixed effects $\left(\gamma_{y}(\tau)\right)$. Absolute values of stratified bootstrapped $t$ statistics are given in parentheses (1,000 iterations). Stratification is detailed in Materials and Methods. 
Table S12: Regression Results Obtained for Statistics

\begin{tabular}{|c|c|c|c|c|}
\hline & \multirow[b]{2}{*}{$\begin{array}{c}\text { Conditional Mean } \\
\text { (OLS) }\end{array}$} & \multicolumn{3}{|c|}{ Quantile Regression } \\
\hline & & $\tau=0.50$ & $\tau=0.85$ & $\tau=0.95$ \\
\hline Intercept & $0.68(0.53)$ & $0.00(0.00)$ & $2.00^{* * *}(0.49)$ & $3.00^{* * *}(0.63)$ \\
\hline$t=-2$ & $-0.65^{* *}(0.30)$ & $-0.00(0.00)$ & $-2.00^{* * *}(0.49)$ & $-3.00^{* * *}(0.47)$ \\
\hline$t=-1$ & $-0.45(0.30)$ & $-0.00(0.00)$ & $-1.00^{* *}(0.44)$ & $-2.00^{* * *}(0.47)$ \\
\hline$t=1$ & $0.94^{* * *}(0.30)$ & $1.00^{* * *}(0.00)$ & $1.00^{*}(0.52)$ & $2.00^{* * *}(0.52)$ \\
\hline$t=2$ & $1.81^{* * *}(0.30)$ & $2.00^{* * *}(0.39)$ & $3.00^{* * *}(0.51)$ & $5.00^{* * *}(0.55)$ \\
\hline$t=3$ & $2.07^{* * *}(0.30)$ & $2.00^{* * *}(0.16)$ & $3.00^{* * *}(0.50)$ & $6.00^{* * *}(0.67)$ \\
\hline $\mathrm{t}=4$ & $2.19^{* * *}(0.30)$ & $2.00^{* * *}(0.13)$ & $3.00^{* * *}(0.55)$ & $6.00^{* * *}(0.82)$ \\
\hline$t=5$ & $2.26^{* * *}(0.31)$ & $2.00^{* * *}(0.27)$ & $3.00^{* * *}(0.61)$ & $7.00^{* * *}(0.82)$ \\
\hline$t=6$ & $2.14^{* * *}(0.31)$ & $2.00^{* * *}(0.42)$ & $3.00^{* * *}(0.60)$ & $7.00^{* * *}(0.87)$ \\
\hline $\mathrm{t}=7$ & $2.10^{* * *}(0.31)$ & $2.00^{* * *}(0.47)$ & $3.00^{* * *}(0.53)$ & $7.00^{* * *}(0.88)$ \\
\hline$t=8$ & $1.92^{* * *}(0.31)$ & $2.00^{* * *}(0.50)$ & $3.00^{* * *}(0.56)$ & $7.00^{* * *}(1.07)$ \\
\hline$t=9$ & $1.84^{* * *}(0.32)$ & $1.00^{* * *}(0.13)$ & $3.00^{* * *}(0.59)$ & $7.00^{* * *}(1.07)$ \\
\hline$t=10$ & $1.74^{* * *}(0.32)$ & $1.00^{* * *}(0.07)$ & $3.00^{* * *}(0.59)$ & $6.00^{* * *}(1.19)$ \\
\hline$t=11$ & $1.67^{* * *}(0.32)$ & $1.00^{* * *}(0.04)$ & $2.00^{* * *}(0.62)$ & $7.00^{* * *}(1.53)$ \\
\hline$t=12$ & $1.51^{* * *}(0.33)$ & $1.00^{* * *}(0.09)$ & $2.00^{* * *}(0.59)$ & $6.00^{* * *}(1.28)$ \\
\hline$t=13$ & $1.46^{* * *}(0.33)$ & $1.00^{* * *}(0.27)$ & $2.00^{* * *}(0.69)$ & $5.00^{* * *}(1.31)$ \\
\hline$t=14$ & $1.32^{* * *}(0.34)$ & $1.00^{* * *}(0.30)$ & $1.00(0.70)$ & $6.00^{* * *}(1.85)$ \\
\hline$t=15$ & $1.12^{* * *}(0.34)$ & $1.00 *(0.50)$ & $1.00(0.70)$ & $4.00^{* *}(1.71)$ \\
\hline
\end{tabular}

The sample consists of 2,584 research articles published from 1985 to 2000. The base category for the age of the paper is 0 and, for the year of citation, the base is 1985. All columns include controls for year-of-citation fixed effects $\left(\gamma_{y}(\tau)\right)$. Absolute values of stratified bootstrapped $t$ statistics are given in parentheses (1,000 iterations). Stratification is detailed in Materials and Methods. 
Table S13: Selected Journals, by Field of Research

\begin{tabular}{|c|c|c|}
\hline Field of Research & Journal & \# Articles \\
\hline \multirow[t]{5}{*}{ Astronomy and Astrophysics } & Astronomical Journal & 908 \\
\hline & Astronomy \& Astrophysics & 2413 \\
\hline & Astrophysical Journal & 4218 \\
\hline & Icarus & 456 \\
\hline & Publications of the Astronomical Society of the Pacific & 383 \\
\hline \multirow[t]{5}{*}{ Biochemistry } & Analytical Biochemistry & 1204 \\
\hline & Biochemical Journal & 2314 \\
\hline & Biochemistry & 3915 \\
\hline & Journal of Biological Chemistry & 9138 \\
\hline & Nucleic Acids Research & 1858 \\
\hline \multirow[t]{5}{*}{ Biology } & Bioscience & 143 \\
\hline & Cell & 866 \\
\hline & Journal of Experimental Biology & 583 \\
\hline & Philosophical Transactions of the Royal Society of London Series B & 327 \\
\hline & Proceedings of the Royal Society B-Biological Sciences & 365 \\
\hline \multirow[t]{5}{*}{ Economics } & American Economic Review & 1107 \\
\hline & Econometrica & 363 \\
\hline & Journal of Political Economy & 401 \\
\hline & Quarterly Journal of Economics & 303 \\
\hline & Review of Economic Studies & 297 \\
\hline \multirow[t]{5}{*}{ Finance \& Journal of Banking } & Finance & 440 \\
\hline & Journal of Finance & 502 \\
\hline & Journal of Financial and Quantitative Analysis & 231 \\
\hline & Journal of Financial Economics & 298 \\
\hline & Review of Financial Studies & 171 \\
\hline \multirow[t]{5}{*}{ Mathematics } & Acta Mathematica & 115 \\
\hline & Advances in Mathematics & 408 \\
\hline & Annals of Mathematics & 291 \\
\hline & Inventiones Mathematicae & 701 \\
\hline & Journal of the American Mathematical Society & 94 \\
\hline \multirow[t]{5}{*}{ Medicine } & American Journal of Medicine & 783 \\
\hline & British Medical Journal & 1420 \\
\hline & Jama-Journal of the American Medical Association & 1057 \\
\hline & Lancet & 1245 \\
\hline & New England Journal of Medicine & 729 \\
\hline \multirow[t]{5}{*}{ Physics } & Physical Review A & 2982 \\
\hline & Physical Review B & 2902 \\
\hline & Physical Review C & 1502 \\
\hline & Physical Review D & 232 \\
\hline & Physical Review Letters & 4981 \\
\hline \multirow[t]{5}{*}{ Political Science } & American Journal of Political Science & 349 \\
\hline & American Political Science Review & 327 \\
\hline & Comparative Political Studies & 159 \\
\hline & Journal of Politics & 309 \\
\hline & Politics \& Society & 122 \\
\hline \multirow{5}{*}{ Psychology } & Psychological Medicine & 667 \\
\hline & Psychological Review & 129 \\
\hline & Psychological Science & 329 \\
\hline & Psychophysiology & 486 \\
\hline & Psychosomatic Medicine & 433 \\
\hline \multirow[t]{5}{*}{ Sociology } & American Journal of Sociology & 261 \\
\hline & American Sociological Review & 380 \\
\hline & Social Forces & 348 \\
\hline & Sociological Methodology & 52 \\
\hline & Sociological Methods \& Research & 126 \\
\hline \multirow[t]{5}{*}{ Statistics } & Annals of Statistics & 784 \\
\hline & Biometrika & 629 \\
\hline & Journal of the American Statistical Association & 1017 \\
\hline & Journal of the Royal Statistical Society Series B-Statistical Methodology & 80 \\
\hline & Statistical Science & 74 \\
\hline
\end{tabular}

